\title{
Rapid-cycle brainstorming: facilitating whole- systems change in time- and scheduling-challenged health care settings
}

This article was published in the following Dove Press journal:

Journal of Healthcare Leadership

5 October 2010

Number of times this article has been viewed

\author{
Kenneth Zakariasen' \\ Isabel Henderson ${ }^{2}$ \\ 'Leadership and Organizational \\ Change Studies Initiative, School of \\ Public Health, University of Alberta, \\ Edmonton, Alberta, Canada; ${ }^{2}$ Glenrose \\ Rehabilitation Hospital, Alberta \\ Health Services, Edmonton, Alberta, \\ Canada
}

\begin{abstract}
Whole-systems approaches to organizational change dominate the contemporary change literature. They focus on widespread engagement of people within organizations, individual and collective ownership of both process and results, and encouragement of creativity and optimism regarding the future. One potential barrier to using whole-systems methods in health care is the frequent recommendation to bring many people together at the same time, sometimes for several days. In health care, it is very difficult to find blocks of time when a group can come together, even when the target unit is relatively small. Rapid-cycle brainstorming is an alternative process for using a whole-systems change method, in this case appreciative inquiry, in a time-efficient, effective manner for change planning in health care. It was used in this case to facilitate strategic planning for a hospital-based dental service for geriatric patients and persons with disabilities. The goals of this method for applying a whole-systems approach to change planning are (1) to minimize the time required to effectively work through the whole-systems process, while at the same time (2) to maximize the engagement of participants, (3) to develop creative synergism between small groups addressing specific planning topics, and when called for (4) to be able to facilitate the involvement of large numbers of individuals across an organization.
\end{abstract}

Keywords: appreciative inquiry, strategic planning, future directions

\section{Introduction}

Whole-systems approaches to organizational change have become the predominant theme in the contemporary change literature. The latest edition of The Change Handbook by Holman and Devane ${ }^{1}$ includes over 60 chapters on the various wholesystems methods that are available today. These methods are designed to focus on the widespread engagement of people at all levels within organizations, the fostering of a sense of individual and collective ownership in both the process and the results, and the encouragement of both innovation and optimism regarding the future of the organization. At their best, whole-systems approaches engage as many people as possible at all levels of an organization, and often beyond, in rich discourse about both existing organizational strengths, and what the ideal organization would look like and how it could become reality. However, it must be recognized that to achieve this, many important factors must be in place, eg, organizational leaders clearly committed to encouraging the participation of people from throughout the organization, facilitators knowledgeable about and effective at designing and guiding the process, and participants willing to engage in the process by sharing their own ideas and thoughts and by listening to others.
Correspondence: Kenneth Zakariasen 3-50P University Terrace, 8303 - II 2 St, Edmonton, Alberta T6G 2T4, Canada Tel + I-780-492-1907

Fax + I-780-492-0364

Email ken.zakariasen@ualberta.ca 
It is the aim of whole-systems approaches to offer methods for change that lead to sustainable and resource-effective change results, whether the target is the whole organizational system or subsystems within the organization. Although our own observations, and numerous case reports in the literature, are very supportive of whole-systems change, the evidence is clearly not as strong as might be offered through randomized clinical trials research. However, such research is very difficult to design and pursue with regard to organizational systems. Thus, we must primarily rely on case reports from whole-systems interventions with regard to both immediate outcomes and longer-term sustainability.

Encouraging, though very indirect, evidence supporting whole-systems change is the increasingly widespread interest in and adoption of whole-systems change methods in the face of considerable failure of traditional top-down methods. Organizational strategic plans were primarily topdown efforts in the past, and a favorable estimate from the "top-down" era for strategic plan implementation was that only about one-third of corporate strategic plans were actually implemented. ${ }^{2}$ We have heard other estimates indicating far lower implementation rates. Organizations are looking for more effective change planning methods, and the emphasis today is clearly in the whole-systems change direction. ${ }^{1}$

An article published in 2002, addressing why wholesystems change processes are so important in public organizations and communities, is even more apropos today than it was then. The authors say the following, "As American society becomes increasingly diverse and public issues more complex, traditional problem-solving methods-based on hierarchical authority, taking charge, and giving direction-come up short. Issues such as teen pregnancy, traffic congestion, homelessness, violence, educational reform, economic development, energy conservation, and countless others, are interconnected and impact virtually every segment of society. As public organizations shift from traditional hierarchical structures to more flexible, participative, networking ones, leaders need change processes that foster the engagement and commitment of many more people, ... ." ${ }^{3}$ The need for organizations that facilitate ongoing interaction, experimentation and learning, innovation, broad stakeholder engagement, and systems change was actually extensively addressed years before this 2002 article. ${ }^{4-6}$ Given the recent worldwide economic debacle and the machinations in the United States regarding health care reform, it would be hard to argue that the private sector is any less complex than the public sector. Clearly, a great many of the "old ways" do not work in today's world.
One potential barrier to the use of whole-systems approaches to change, particularly in health care, is the frequent recommendation to bring many people from the organization together at the same time, sometimes for several days. For example, appreciative inquiry (AI) is a very popular whole-systems method in use today. ${ }^{7}$ Cooperrider and Whitney" have stated that "The AI Cycle can be as rapid and informal as a conversation with a friend or colleague, or as formal as an organization- or community-wide process involving every stakeholder group."' One recommended and frequently adopted formal format for using AI is the Appreciative Inquiry Summit. ${ }^{8}$ As described by Cooperrider et $\mathrm{al}^{9}$ "the duration is generally three to four days and involves 50 to 2,000 participants or more." Another author states that "some Appreciative Inquiry processes take place over a period of days, or even hours - and others unfold over an extended period of time," while still another author states "The Appreciative Inquiry process is very flexible ... it can and should be customized to the needs of each individual organization." 10,11 As is indicated above by these various comments and descriptions, AI is indeed a very flexible and adaptable method, which lends itself well to use with the rapid-cycle brainstorming method we describe in this article.

Another intriguing whole-systems approach is open space technologies (OST). ${ }^{12}$ Similar to AI, OST suggests an event of several days duration involving large numbers of individuals from the organization. In this method, the multiday session begins with no agenda, and the first order of business is a very dynamic process where the agenda is generated and self-managed by the group itself, ie, creating the agenda by including issues for discussion that any group members believe are germane to the central task for the change planning event. It will be interesting to see how this innovative whole-systems method can be adapted to work within the constraints we have identified within the health care environment.

A partial adaptation of OST, ie, the agenda-generating process, is discussed later in this article, as is the World Café concept used in combination with AI in rapid-cycle brainstorming. World Café is, like OST, a whole-systems approach that has become popular in organizational change facilitation. ${ }^{1}$

Within the health care arena, which cuts across numerous small and large clinical disciplines and administrative units, and often operates on a 24/7 basis, the logistics of bringing together many people from across the organization at the same time and place for even 1 full day together can be a very difficult undertaking at best. The real challenge in health care 
becomes one of gaining the advantages of a whole-systems change approach within the time and scheduling limitations of health care organizations. Rapid-cycle brainstorming is a methodology that makes this possible.

This article describes this alternative method for using a whole-systems change process in a rapid, time-efficient, and effective manner for change planning, in this case specifically for strategic planning. AI is the whole-systems change methodology adapted to the rapid-cycle brainstorming process and then subsequently used to facilitate strategic planning for a hospital-based dental service for geriatric patients and persons with disabilities. The goals of this method for applying a whole-systems approach to change planning are (1) to minimize the time required to effectively move through the sequential phases of the whole-systems process, while at the same time (2) to maximize the engagement of participants, (3) to develop creative synergism between small groups addressing specific planning topics, and when called for (4) to be able to facilitate the involvement of large numbers of individuals across the organization.

\section{Overview of the Al}

$\mathrm{AI}$ advocates an inquiry process that is referred to as the $4 \mathrm{D}$ cycle. ${ }^{9}$ AI focuses first on the current strengths of the organization, those times when the organization was at its best, which it calls the "discovery" phase. It then brainstorms the many various possibilities of what the organization could potentially look like when at its best, which it refers to as the "dream" phase. Following this creative brainstorming, the AI process focuses on designing the organization for the future where the best of the current organization, ie, its "positive core," is preserved and enhanced and where the essential features of the ideal organization become the driving force for the organization's future actions. This is the "design" phase. The final phase in the 4D cycle, the "destiny" phase, focuses on making the new design for the future of the organization become reality. People are the core of the organization, and this phase is really about an energized group of people taking responsibility for actions that create a new organizational destiny, ie, implementation of the new design for the organization thus making the new design become the new reality. This organizational change may take place in one specific area, eg, access to care, or across an organization in many key areas as a new strategic plan.

AI generates very positive data about an organization, particularly stories about best experiences, through individual one-on-one AI interviews and through interviews and group discussion in AI workshops or summit sessions.
The most important feature of the AI interview and the AI group discussions is the unconditionally positive AI question. ${ }^{13}$ These questions focus on topics such as "When has our organization been at its very best and what was it doing then that put it at its best?" and "If you could transform this organization in any ways you wished, what are the top three things you would do to increase its effectiveness, its vitality?" The stories uncovered during AI interviews/discussions have a powerful energizing effect on people.

In one effective AI approach, mini-AI interviews are first conducted using very general AI questions. ${ }^{14}$ These mini-interviews generate data that help the organization identify key themes that are important to the future of the organization. From these themes, key strategic topics are developed for a more focused, rather than general, inquiry, eg, "Service delivery in the context of superb customer service" or "Our people strategy ... building and strengthening the essential foundation for our success." In AI, such topics are often referred to as affirmative topics, although we prefer to call them key strategic topic areas. These are the central focus for much of the AI process. ${ }^{9,13,14}$ Specific AI questions are then developed around each of these topics, and a series of AI interviews/small group discussions and large group sessions are typically held within the organization. These take the form of AI workshops or summits.

The AI workshops and the AI summits can differ significantly in the amount of scheduled time that is utilized, the numbers of individuals involved, and the scope of the 4D cycle coverage that is possible in a single event. For example, an AI summit may run for up to 3-4 days and cover all four phases of the 4D cycle. AI workshops, on the other hand, may typically run for as little as several hours or up to a day in length and cover only a portion of the 4D cycle, eg, the discovery phase. Thus, when such workshops are used, they are usually conducted as a series of two to four workshops over time. In either case, these are often difficult to conduct in many health care settings due to the ever-present time and scheduling constraints. The rapid-cycle brainstorming method allows AI and other adaptable whole-systems methods to be used in spite of these constraints.

\section{Rapid-cycle brainstorming}

The reality in most health care organizations is that it is very difficult to find common blocks of time when a broadspectrum of individuals can come together for planning activities, even when the target unit is relatively small as illustrated by the Glenrose Rehabilitation Hospital (GRH) dental service example. Yet, planning strategically for the future 
is a critical undertaking, especially in today's fast-paced world of change. Given these frequent scheduling and time limitations, we began to examine possible ways in which whole-systems methods could be modified to maximize creativity and productivity during time-limited group "brainstorming" engagements, and at the same time, minimize the number of workshops needed to effectively work through the sequential phases of the planning process.

At this point, it is important to raise a caution about the concept of brainstorming itself and to bring a proper perspective to its place within the context of whole-systems approaches to change. Although brainstorming is a very popular group creativity method, the evidence does not suggest that it is more effective than individuals working independently: in fact the opposite appears to be the case. ${ }^{15-17}$ However, it should be recognized that this evidence refers to creative productivity, ie, the numbers of ideas generated, which has its own problems in interpretation.

However, in whole-systems approaches, many more people are engaged in the process than in top-down planning efforts, and idea productivity should actually increase overall. In addition, a real advantage is that a great many of the ideas for change/vision building will originate at the level where work is being done, which is difficult to achieve even modestly with top-down methods. ${ }^{18}$ Using wholesystems methods, groups of individuals brainstorm ideas together regarding both organizational effectiveness and future directions. This has positive implications relative to building organizational teamwork, encouraging engagement of many people, and empowering people by seeking their ideas across the organization, and importantly, to instilling a sense of ownership of the results of the process. ${ }^{1,19}$ This is particularly evident when contrasted with the often negative responses from people when they are handed a new top-down vision for an organization in which their involvement and ideas were never sought. The following quote from Harvard Business Essentials: Managing Change and Transition illustrates this problem well: "Top-driven change also creates people problems. People resist having solutions imposed on them by individuals who lack intimate familiarity with their day-to-day operations. Their resistance is expressed through a lack of motivation and commitment to change." 18

If an organization does elect to use a whole-systems approach to change, it must commit to truly involving representation from all segments of the organization. If this does not occur, it may be perceived that upper management is "just going through the motions" for appearances sake. It is particularly critical that members of the upper management team be actively and enthusiastically involved in the process. This is especially important in showing commitment to this new approach if past planning and change processes have essentially been top-down in nature. Other important reasons for active, enthusiastic involvement of upper management are to articulate a "big picture" perspective of the organization and its current external and internal environments, management's perspective on change and the future, and a sense of what is doable and sustainable as new ideas are generated and considered. Ultimately, management will need to "signoff" on a plan that it can enthusiastically support, and upper management's continuous input and guidance during the process are thus critical.

It should also be emphasized that leadership research has clearly shown that effective leaders inspire a shared vision in their organizations. ${ }^{20}$ Leaders need to listen to what is important to others, and they need to seek the advice and ideas of others from across the organization. One of the most effective opportunities for leaders to do this is through their support of, and participation in, whole-systems planning activities. This sends a strong message that they are not simply another top-down organization. An excellent example of this is Roadway Express Inc, and the way they built the effectiveness of the organization through an AI planning process across the organization. ${ }^{21}$

We have had the opportunity to participate in or lead a great many brainstorming sessions over several decades. Reflecting on these experiences, the use of very short timelimited sessions focusing intensely on one topic during each "mini" session appears not only to encourage and hold the participants' interest and level of enthusiasm but also to consistently generate a rapid flow of ideas. For example, in one international professional organization, this worked so well that the executive office team formally adopted the short, rapid, single-topic brainstorming method as their preferred method to generate new ideas. Whenever a team member needed innovative ideas in their area of responsibility, they had only to request such a brainstorming session. ${ }^{22}$ This simple concept does, of course, require a much more complete integrated framework to accommodate major change/full strategic planning efforts. With these observations in mind, the following brainstorming methodology was developed as a three-phase process. This methodology does have some elements in common with brainstorming-group passing technique, but very significant differences relative to brainstorming topic selection, as well as the significant differences in process and the way people interact, the targeted types of questions crafted for brainstorming, and the way 
that ideas are managed and organized into implementable key future directions for an organization. ${ }^{23}$

\section{The rapid-cycle brainstorming methodology}

The three phases of the rapid-cycle brainstorming method involve prebrainstorming preparation, the actual rapid-cycle brainstorming itself, and the design and implementation of the new future based on the ideas generated during the brainstorming session. These three phases are summarized in Table 1 and explained in detail in individual narrative sections. Table 1 also includes a side-by-side comparison of the small and large group differences when using rapidcycle brainstorming. Following the discussion of rapid-cycle brainstorming in smaller organizations or units, a detailed discussion covers the additional processes, which allow this method to be used in large organizations with very substantial numbers of participants.

It is important to acknowledge at this point that it is very helpful to have individuals experienced in group process facilitating the following three phases. In large organizations, there are often individuals within the organization who are experienced in group process work, such as brainstorming, vision building, and strategic planning. One or more of these individuals, depending on the size of the organization, should be partially seconded to the rapid-cycle brainstorming process for its duration. Such individuals should have no difficulty in planning the logistics and activities necessary for successful implementation of the rapid-cycle process. If the organization does not have such individuals available internally, it would be beneficial to contract such individuals to work with the organization and participants to successfully work through the process to the final results.

\section{Phase I: prebrainstorming preparation Number and focus of key strategic topics}

First, the number and focus of key strategic topics for consideration should be determined. Different whole-systems methods do this in different ways. This is a critically important undertaking to the success of change planning. We would recommend reading about how this is done in AI, OST, and several other whole-system approaches to find a method that your organization will feel comfortable with and trust. ${ }^{1,12,14}$ Our example from the GRH will show later how this was done using a series of AI mini-interviews. Five to seven fairly broad key topics are a very manageable size..$^{9}$ Keep in mind that multiple specific topics can be addressed under each of the broad-based general topics. For example, patient "customer service" and "access to care" are two topics that many health organizations are addressing. Topics such as these are broad in scope and can facilitate wide-ranging discussions and idea generation for effective change.

\section{Creation of planning clusters}

Ideally, everyone in an organization, who is interested in being involved in the planning process, should have the opportunity to participate. From a practical standpoint, some people will choose not to participate and others may have scheduling or other conflicts. However, every effort should be made to have representation from all levels within the organization. The total number of participants in the planning process should be determined. If this is a large planning group, it should be divided into smaller planning groups with a maximum size of approximately 25 individuals each. We have termed these smaller planning groups as "planning clusters." In a small organization or organizational subunit, there may only be one planning cluster of this size or smaller, which was the situation for the GRH dental service. At this point, to simplify the initial understanding of the rapid-cycle brainstorming process, we will assume a small organization or organizational subunit and only one planning cluster. Then, we will examine how this process can be modified to accommodate large numbers of planning participants using multiple planning clusters and collaborative bridging activities.

\section{Creation of brainstorming teams}

The planning cluster is then divided into brainstorming teams of three to five persons per team. For example, let us assume the planning cluster numbers 20 and that we divide the cluster into five groups of four persons each. An example in health care could be a small outpatient medical clinic or a specialized nursing unit within a hospital. There is not any specific "right size" to these teams, except that they should be small enough that each person can easily and comfortably participate and that the team can cover an individual topic thoroughly and quickly. We would recommend that the brainstorming teams be kept on the smaller side whenever practical, eg, three per team, and that individuals be randomized into these small teams. As discussed previously, the ideal is to involve as many people as possible from the organization in the process. As a result, planning clusters might range from a single cluster of 10 in a very small organization or organizational subunit to many clusters of 25 involving a total of hundreds or more participants in a large organization. 
Table I Overview of the 3 phases of rapid-cycle brainstorming for small- and large-size planning initiatives

\begin{tabular}{|c|c|c|c|}
\hline Rapid-cycle phase & Activities & $\begin{array}{l}\text { Application to a small } \\
\text { single organizational unit } \\
\text { or other small-size } \\
\text { planning initiatives }\end{array}$ & $\begin{array}{l}\text { Application to full } \\
\text { organizational or other } \\
\text { large-size planning } \\
\text { initiatives }\end{array}$ \\
\hline \multirow[t]{3}{*}{$\begin{array}{l}\text { Phase I: prebrainstorming } \\
\text { preparation }\end{array}$} & $\begin{array}{l}\text { Determine number (usually } 5-7 \text { ) and } \\
\text { focus of strategic topics for } \\
\text { consideration using appreciative inquiry } \\
\mathrm{Al} \text { approach }\end{array}$ & $\begin{array}{l}\text { X } \\
\text { Use of mini-interviews } \\
\text { involving a relatively small } \\
\text { number of participants, likely } \\
\text { in the } 12-20 \text { range }\end{array}$ & $\begin{array}{l}\text { X } \\
\text { More extensive process for } \\
\text { topic selection makes use of } \\
\text { mini-interviews involving broad- } \\
\text { based and larger numbers of } \\
\text { participants, likely } 25 \text { or more }\end{array}$ \\
\hline & $\begin{array}{l}\text { Creation of planning clusters (ideally up } \\
\text { to approximately } 25 \text { people) }\end{array}$ & $\begin{array}{l}\text { X } \\
\text { May use only I planning cluster }\end{array}$ & $\begin{array}{l}\text { X } \\
\text { Makes use of multiple planning } \\
\text { clusters }\end{array}$ \\
\hline & $\begin{array}{l}\text { Creation of brainstorming teams within } \\
\text { each planning cluster ( } 3-5 \text { people/team) }\end{array}$ & $x$ & $x$ \\
\hline \multirow[t]{4}{*}{$\begin{array}{l}\text { Phase 2: rapid-cycle } \\
\text { brainstorming }\end{array}$} & $\begin{array}{l}\text { Each strategic topic area brainstormed } \\
\text { individually for } 15-20 \text { min by each } \\
\text { brainstorming team with feedback } \\
\text { recorded. }\end{array}$ & $x$ & $\begin{array}{l}\text { X (clusters may meet } \\
\text { individually over several days or } \\
\text { weeks based on the number of } \\
\text { planning clusters and scheduling) }\end{array}$ \\
\hline & $\begin{array}{l}\text { Each brainstorming team summarizes } \\
\text { the ideas generated for their final } \\
\text { brainstorming topic }\end{array}$ & $x$ & $x$ \\
\hline & $\begin{array}{l}\text { Each brainstorming team presents to } \\
\text { the planning cluster a summary of the } \\
\text { ideas generated for their respective } \\
\text { topic for validation }\end{array}$ & $\mathrm{x}$ & $\mathrm{x}$ \\
\hline & $\begin{array}{l}\text { Planning cluster determines next steps } \\
\text { reuse of small working subgroup or } \\
\text { workshop session to draft a future } \\
\text { directions document }\end{array}$ & $\mathrm{x}$ & $x$ \\
\hline \multirow[t]{2}{*}{$\begin{array}{l}\text { Phase 3: designing and } \\
\text { implementing a new future }\end{array}$} & $\begin{array}{l}\text { Drafting of 5-7 key future directions by } \\
\text { a working subgroup and then provided } \\
\text { to participants in advance of phase } 3 \\
\text { workshop } \\
\text { or } \\
\text { Wait for planning cluster to draft key } \\
\text { future directions at phase } 3 \text { workshop }\end{array}$ & $x$ & $\begin{array}{l}\text { X (The smaller working sub- } \\
\text { groups may meet individually } \\
\text { over several days or weeks } \\
\text { based on the number of planning } \\
\text { clusters and scheduling) }\end{array}$ \\
\hline & $\begin{array}{l}\text { Phase } 3 \text { workshop: use of up to half-day } \\
\text { session by each planning cluster to } \\
\text { finalize the key strategic directions } \\
\text { that were: Drafted in advance for their } \\
\text { consideration by a working subgroup. } \\
\text { or } \\
\text { Drafted by whole planning cluster at } \\
\text { this workshop }\end{array}$ & $\begin{array}{l}\text { X } \\
\text { Includes identification of action } \\
\text { steps to move forward with } \\
\text { strategic directions }\end{array}$ & $\begin{array}{l}\text { X (clusters may meet individually } \\
\text { over several days or weeks } \\
\text { based on the number of planning } \\
\text { clusters and scheduling) }\end{array}$ \\
\hline Next steps & $\begin{array}{l}\text { Use of bridging process to facilitate the } \\
\text { integration of the key strategic } \\
\text { directions recommended by each } \\
\text { planning cluster }\end{array}$ & NA & $x$ \\
\hline
\end{tabular}

Abbreviations: $\mathrm{Al}$, appreciative inquiry; NA, not applicable.

\section{Special considerations in selecting planning cluster and brainstorming team members}

In single planning cluster processes, only 25 participants or less are involved, and the planning cluster includes all participants. Thus, no special selection considerations are involved. In a multicluster process, most participants can be placed in a planning cluster according to their scheduling availability. Ideally, each planning cluster would include a range of individuals from across the organization. However, care should be taken to make sure that one or more members of the upper management team are participants in each of the planning clusters. The credibility of the whole-systems 
process is greatly enhanced when the upper management is actively and enthusiastically part of the process, especially when these individuals continually ground the discussions in the broad organizational perspective.

There are three important considerations with regard to selecting the members of the small brainstorming teams. The first relates to brainstorming teams that include one or more members of the management team, and whether this will discourage nonmanagement team members from fully participating, ie, a reluctance to bringing forth their opinions and ideas. There is little question that this could indeed occur. However, two things can help to mitigate this. The first is to send a consistent message right from the beginning of the planning process that the organizational leadership really does want members of the organization to participate in open dialog and constructive idea generation that can increase the effectiveness of the organization. This message is critical, particularly if the organization has primarily been a top-down organization. The second thing is for management team members to proactively encourage such dialog and idea brainstorming during their individual brainstorming team activities.

The second consideration in selecting members for the small brainstorming teams is whether to have a supervisor and 1 or more of their direct reports on the same brainstorming team. Although many supervisors do have very open and trusting lines of communication with their supervisees, and being on the same team would not likely be problematic, this is difficult to predict and it is probably prudent to just avoid this situation whenever possible when selecting the brainstorming teams.

A third consideration in selecting members for the brainstorming teams is to develop a mix of individuals on these teams. In the example of the hospital dental service discussed later in this article, it was not unusual to have a hospital manager, a dental assistant from the dental service, and a university dental faculty member on the same brainstorming team. Each member of the team brought special areas of expertise, knowledge, and organizational perspective to the brainstorming efforts on key strategic topics.

\section{Phase 2: rapid-cycle brainstorming}

The rapid-cycle brainstorming session is the creative activity that energizes people and unlocks their innovative ideas for positive change in the organization. By the end of this session, participants will have had the opportunity to contribute to the development of a progressive vision of what their organization could become at its best. And, during this process, each participant will also have had the opportunity to learn much more about the whole organization and how it works. This certainly correlates well with Peter Senge's concept of the learning organization that he defines as "organizations where people continually expand their capacity to create the results they truly desire, where new and expansive patterns of thinking are nurtured, where collective aspiration is set free, and where people are continually learning to see the whole together."5 It is not hard to imagine that after several cycles of wholesystems planning, an organization could truly begin to become a "learning organization" as described by Senge, one of the most influential management concepts of the 20 th century. ${ }^{24}$

\section{Brainstorming key strategic topics}

This session begins with the planning cluster meeting together first for a short welcome and introduction to the brainstorming process and for assignment to their brainstorming teams. Each team is then assigned a topic to brainstorm for 15-20 minutes, addressing two basic questions. The first question is "What do we do very well right now with regard to (eg, access to care)?" The second question is "What could we do differently or additionally to be even more effective in providing (eg, access to care)?" A very good third question could also be added to the mix, "What would ideal (eg, access to care) look like in our organization if resources and other constraints were not an issue?" These are AI-style questions, and they will yield very useful data about the current strengths of an organization, as well as generating many ideas that can lead to positive change that will increase organizational effectiveness. Each team's responses to the questions are recorded on a flip chart that stays with that topic. There are many different variations on the way AI questions can be written, and there are a number of good sources to guide you in this task. ${ }^{14,25,26}$ As organizations become comfortable using AI, they also become very adept at writing their own AI questions.

The brainstorming teams then move to a new topic every 15-20 minutes until each team has had the opportunity to brainstorm each topic individually. During the introduction to the brainstorming session, instructions are given that following the first round of brainstorming, each team may then be considering topics, which have already been brainstormed by one or more teams. Thus, following the first round, the following instructions pertain: "First review any responses to the two or three questions that previous brainstorming teams may have generated on the topic you are now going to brainstorm. Your team's task is to add to or refine the ideas generated by the team or teams that may have preceded your team on each 
topic." This, in effect, creates a layering of ideas for each topic and ideally a synergism of idea generation among teams as they move from topic to topic considering the ideas that were generated by previous teams. Considering our hypothetical example, the total time spent in brainstorming new ideas for changes to increase organizational effectiveness in each of the key strategic topic areas would be 75 minutes when using 15 minutes per topic.

\section{Brainstorming teams summarize ideas}

Each team is given 20 minutes to summarize the ideas that were generated for their final brainstorming topic by their team and those teams that preceded them.

\section{Team topic-summary report-outs and validations}

The planning cluster then comes back together and each brainstorming team is given approximately 10 minutes to report out to the group a summary of the ideas generated for their final topic and to receive feedback from the other participants regarding the accuracy and completeness of their summary. Each team immediately makes any corrections necessary.

\section{Determination of next steps}

The last task for the planning cluster is to decide upon their desired next steps. For example, do they want a small working subgroup to take all of the ideas generated and develop a draft set of new directions for the organization that the planning cluster can then consider at a subsequent workshop session? Or, would they rather pursue the drafting of future directions together as a whole planning cluster at the next workshop session? This task should take only about 10 minutes. If a small subgroup is the preferred course of action, the planning cluster group should select two to three individuals at this time to serve as the working subgroup. It is also recommended that all of the flip-chart data be transcribed following the session and provided to each of the planning cluster participants. This will give each participant an opportunity to review all of the ideas generated by the brainstorming teams on each topic, as well as recording any further ideas they may have in preparation for the next planning cluster workshop session.

\section{Phase 3: designing and implementing the new future}

This phase involves determining the directions for the future of the organization or organizational unit that has been identified during the brainstorming discussions around the key topic areas and the identification of action steps that will begin forward movement on these strategic directions.

Several weeks following the brainstorming session, the planning cluster comes back together again to articulate a set of directions for the future of the organization or organizational subunit. The time span between the first and second planning cluster workshop sessions could be shorter if the planning cluster will be drafting key directions together, or possibly even longer if a small working group takes on the drafting task, in which case they will probably require 2 or more short meetings to complete their work. The data generated during the rapid-cycle brainstorming session should provide numerous ideas regarding both strengths within the organization that can be built upon and new ideas for transforming the organization that should work together to result in a stronger, more progressive, and more effective organization.

As discussed previously, the planning cluster can draft the new directions together, or can have a small working group develop a set of draft directions, for the whole cluster group to consider. Either way can be very effective. However, our experience has been that the planning cluster would often like a small working group to prepare an initial draft of potential directions for their consideration, and we would recommend this process. As you will see in our example at the GRH dental service, this can work very well as long as the planning cluster has the opportunity to modify and rewrite these initial draft directions.

It undoubtedly must seem like a big "leap of faith" to believe that the key future directions for an organization can be cogently articulated during the short time a planning cluster has together during the second workshop. However, because of the involvement of upper management throughout the process, the extensive prework done before the first workshop, the small group work done between workshops, and the ever tighter focus on the future that the process creates makes this articulation of future directions actually possible during the second workshop. But, the qualifier here is that this holds true only when the organization or organizational subunit is small enough that there is only one planning cluster.

As we will see later in this article, in a large organization that requires multiple planning clusters, each planning cluster can usually develop its recommendations for key future directions by the end of the second workshop. However, a working group of representatives from each of the clusters must then be formed as a bridging process to bring the recommendations for key future directions from all of the planning clusters together to categorize, group, com- 
bine, rewrite as necessary, and prioritize to arrive at a set of five to seven key strategic directions for the organization. This working group, as in all preceding parts of the planning process, must have significant representation from the upper management of the organization and should be facilitated by either the internal or external consultant(s) who have been with the process since it began.

\section{The resulting key strategic directions}

Five to seven key directions, most often developed directly from the original key strategic topics, is a very manageable size with which to work. However, this is not necessarily a one-to-one correlation. We have seen instances where two key topics have been collapsed into one broad future direction, and alternatively where one key topic has resulted in two separate future directions. These occurrences are normal and dependent directly on the data generated.

\section{Time requirements for the two planning sessions}

Ideally, the first planning session should be one half day or slightly less in length, and the second planning session should be approximately from 2 hours up to 1 half day in length. The number of key strategic topics to be brainstormed and the length of time scheduled for each topic are the prime determinants in how long the rapid-cycle brainstorming session, ie, first planning cluster workshop session, will take. For example, a session with five strategic topics and five brainstorming teams of up to five participants each, spending 15 minutes brainstorming each topic, will result in a session that will require just under three hours. On the other hand, a session with seven strategic topics and seven brainstorming teams of up to five participants each, spending 15 minutes brainstorming each topic, will result in a session that will require approximately 3 hours and 40 minutes. The time allocations break down is shown in Table 2.

In the case of five topics, up to 25 participants can be included in the planning cluster. In the case of seven topics,

Table 2 Brainstorming session time allocations

\begin{tabular}{lll}
\hline & $\mathbf{5}$ topics & $\mathbf{7}$ topics \\
\hline $\begin{array}{l}\text { I. Welcome and } \\
\text { introduction to the session }\end{array}$ & $15 \mathrm{~min}$ & $15 \mathrm{~min}$ \\
$\begin{array}{l}\text { 2. Rapid-cycle } \\
\text { brainstorming }\end{array}$ & $75 \mathrm{~min}$ & $105 \mathrm{~min}$ \\
$\begin{array}{l}\text { 3. Teams summarizing } \\
\text { brainstorming results }\end{array}$ & $20 \mathrm{~min}$ & $20 \mathrm{~min}$ \\
$\begin{array}{l}\text { 4. Report-outs from each } \\
\text { brainstorming team }\end{array}$ & $50 \mathrm{~min}$ & $70 \mathrm{~min}$ \\
$\begin{array}{l}\text { 5. Next steps } \\
\text { Time required for sessions }\end{array}$ & $10 \mathrm{~min}$ & $10 \mathrm{~min}$ \\
\hline
\end{tabular}

up to 35 participants can be accommodated. We would recommend using the time estimates as approximations of the minimum and maximum amounts of time necessary for productive brainstorming sessions. Having conducted many such brainstorming sessions, the number of key strategic topics is more often in the five rather than in the seven range, and 15 minutes per topic is not an unreasonable time limit, particularly when the size of the brainstorming teams can be held closer to three than to five participants each. Remember, too, participants are focusing intensely on only one topic at a time, and they have the opportunity to review the ideas generated by each group that preceded them.

During the second workshop session, the planning cluster participants will review the key strategic directions drafted by a small working group and approve them as written, modify them and approve, or rewrite them and approve. This can usually be done in 2-3 hours. However, if the planning cluster has elected to draft the key strategic directions itself, a half-day session should definitely be scheduled. In either case, the planning cluster should also identify important actions to be taken with regard to initiating progress forward for each of the key strategic directions. It would be very surprising if many or most of these actions have not already been suggested during the brainstorming sessions on the original key topic areas.

Most often, scheduling two half-day sessions for the planning cluster to meet and deliberate will be more than sufficient time to accomplish very significant idea generation, the formulation of key strategic directions, and the identification of the action steps necessary to initiate forward movement in these new directions. Keep in mind that this assumes that significant prework and small group work before and between the workshops will be carried out.

\section{Accommodating large numbers of planning participants}

There are several important modifications to the overall rapid-cycle brainstorming process that are necessary to accommodate large numbers of planning participants. The first modification is the use of multiple planning clusters rather than only one cluster. The second modification is a more extensive process for the selection of key strategic topics for the planning process. And, the third modification is the addition of bridging activities that facilitate integration of the key strategic directions for the future that are recommended by each planning cluster into one unified, cohesive set of strategic directions for the organization. 
Since the rapid-cycle brainstorming process uses the planning cluster of approximately 25 people as its essential planning unit, it is relatively easy to add one or more extra clusters to the process in a large organization. For example, where 200 people want to participate in the planning process, eight clusters would accommodate all the participants. Not all clusters need to meet at the same time, ie, they could meet sequentially over a period of time. However, logistically it does simplify and expedite the overall process when more than one cluster can hold workshops at the same time, but independently of each other.

Before the rapid-cycle brainstorming workshop, all those who will be participating should be assigned to both a planning cluster and a brainstorming team within their cluster. The assignments of individuals to clusters will be a function of when the clusters are scheduled and the individual schedules of participants. Thus, to create flexibility for individuals to participate, a combination of simultaneous and sequential brainstorming workshops will provide at least two or more scheduling opportunities for participation. In the previous example of 200 participants, two brainstorming workshops could be held per week over a 4-week period. This would provide a number of scheduling choices for most participants.

The second modification is using a more extensive process for the selection of key strategic topic areas. When an organization is large enough that multiple planning clusters are necessary, it is usually also a much more complex organization with more units and more stakeholders. When you use AI as your whole-systems planning method as we often do, this necessitates the collection of mini-interview data from a broad-based group of constituents across the organization to ensure a "zeroing-in" on the key strategic topic areas of import across the organization. Two examples may help illustrate the contrast that can occur between two organizations in the same discipline. For the GRH dental service described in this article, a small narrowly focused clinical service in a large hospital, 12 mini-interviews were sufficient.

On the other hand, in facilitating strategic planning for a large dental school that included specialty graduate programs, we did over 100 mini-interviews before beginning group brainstorming activities. These were far more interviews than were probably necessary. However, the organization was not only complex but also had an extremely high number of internal and external stakeholders. These many interviews not only facilitated the identification of key strategic topic areas for the planning process but also provided a huge amount of excellent data that were used to better inform the brainstorming process by serving as foundational data provided to each planning participant. In addition, as a highengagement exercise leading to broad-based stakeholder ownership of both the process and the results, it was a very beneficial undertaking.

It should be noted that this particular situation was fairly unique with regard to the number of interviews conducted. In most organizations of this size, we would feel comfortable with substantially fewer of the mini-interviews. However, it is difficult to specify a specific number of interviews that are appropriate for either a small or large organization. The data being collected by the mini-interviews are qualitative data, and the best indicator that you have conducted sufficient interviews is when you begin to see data saturation, ie, additional interviews are not uncovering new data. ${ }^{27}$ In the case of the previous example where 100 mini-interviews were conducted, we would venture to say that we probably would have begun to see data saturation after 25-40 interviews.

The third modification made to accommodate large numbers of planning participants is the addition of bridging activities between planning clusters. Each planning cluster works independently through the three phases of the rapidcycle brainstorming process described previously. At this point, a "bridging" process is necessary to facilitate the integration of the key strategic directions recommended by each planning cluster into a unified set of key strategic directions for the organization. To begin this process, each planning cluster appoints one of its members to serve on a bridging working group. As well, all planning participants should receive a copy of the planning results produced by each planning cluster.

The members of the bridging working group first review the key strategic direction results from each cluster. Their task is to then categorize, group, combine, re-write as necessary, and prioritize these key direction results to arrive at a set of five to seven key strategic directions for the organization. In large, complex organizations, the number of key strategic directions could go as high as 10 . However, beyond that number, it will likely be difficult for people to perceive a unified, cohesive vision of where the organization is headed; instead, they may sense that the organization is trying to go in too many directions at once. We have observed this in some organizations to such an extent that the planning process actually results in fragmented and confused thinking about the organization's directions for the future, instead of resulting in a clear shared vision for the future, which is really one of the primary reasons for using whole-systems approaches.

When the bridging committee has finished drafting the key strategic directions for the organization, they then need to 
identify the high-priority actions for each strategic direction, actions that should begin as soon as possible to begin progress in making these new directions become the organization's new reality. A draft document containing the new strategic directions and initial action steps should be sent to all participants in the planning process asking for any feedback they would like to give. The bridging committee should then consider the feedback and make any modifications to their draft document that they believe are merited.

\section{The GRH dental service}

Established in 1989 through funding from the Northern Alberta Regional Geriatric Program (NARG), the dental clinic was originally located at the Edmonton General Hospital before moving to the GRHa in 1997. Renamed the GRH dental clinic, it specializes in providing comprehensive dental service for the treatment and prevention of oral disease in frail, elderly patients, and adults over 18 years of age with physical disabilities or other care needs. The majority of clients served in the GRH dental clinic are over 65 years of age. Referral sources include GRH inpatient and outpatient programs $(21 \%)$, continuing care $(38 \%)$, and private practice dentists/self-referral (39\%). Approximately 2\% are "healthy" patients, eg, hospital staff, public. The clinic also serves as a teaching facility for residents, fourth-year dental students, and dental hygiene students from the University of Alberta's Faculty of Medicine and Dentistry.

Staffed by five part-time dentists, two full-time dental assistants, and a receptionist/clerk, the clinic is wheelchair accessible and is equipped with both a medilift and a hydraulic wheelchair lift to assist with patient transfers. The clinic sees in excess of 3,000 patient visits yearly. The clinic also provides outreach assessment service to various long-term care facilities and nursing homes within Edmonton and the surrounding area.

\section{Applying "rapid-cycle brainstorming" to the GRH dental service}

We have frequently used "rapid-cycle brainstorming" in single-cluster planning efforts, ie, with a planning cluster of approximately $12-25$ participants. However, this approach

aLocated in Edmonton, Alberta, as one of Canada's premier rehabilitation facilities for children and adults, the Glenrose Rehabilitation Hospital (GRH) offers many highly specialized inpatient and outpatient programs and services for children and adults. Established in 1964 and operating within Alberta Health Services, the Glenrose continues as a leader in geriatric and rehabilitation research, education and clinical programs for residents of Northern and Central Alberta with physical, cognitive, and developmental impairments. can be effectively applied to substantially larger groups by using multiple planning clusters simultaneously and/or sequentially along with the bridging activities discussed previously. The single-cluster vs multiple-cluster designs usually reflect the differing planning needs of a smaller subunit, eg, a dental service, as opposed to planning for an entire organization, eg, a hospital or a medical school. In one recent project of strategic planning in a large medical school, the multicluster approach greatly facilitated widespread stakeholder engagement that would not have been possible using a large group, multiday format.

Before the first workshop for the dental service planning cluster, a mini-AI interview was designed and administered through one-on-one interviews to assess individual perspectives on such questions as "Describe a time when you believe the GRH Dental Service was at its very best," "Describe a time when the GRH Dental Service 'wowed' a patient with customer service, ie, when it exceeded the patient's expectations," and "If you could transform the GRH Dental Service in any way you wished, what three things would you do to heighten its vitality, its effectiveness, its direction?" A broad scope of 12 individuals were interviewed.

The responses to these interview questions, coming from hospital leaders and managers, clinic staff, patients, and associated University of Alberta dental faculty and staff, gave a number of insights into topics that were important to consider when looking at both the current status and future of the GRH dental service. A small working group of three from the hospital and the University of Alberta Department of Dentistry then grouped and condensed the various topics into five broad key strategic topic areas for which specific AI questions were then written.

As an alternative to the AI mini-interview process, the OST agenda-setting process could be used instead. ${ }^{12}$ A short workshop of approximately 1 hour is scheduled, and all planning cluster participants are invited to attend. During this session, participants are encouraged to bring forward topics for discussion during the subsequent planning cluster workshops that they consider important to the organization's future directions. A small working group, as in the case of the AI mini-interviews, then condenses these topics into broad key strategic topics for which AI questions are then written for use during the rapid-cycle brainstorming workshop.

The next step was the first AI planning cluster workshop. The mini-AI interviews, the determination of key strategic topics, and the writing of AI questions for these key strate- 
gic topics are all part of the prebrainstorming preparation "homework" that will lead to creative interactions during the "rapid-cycle brainstorming" workshop. The responses from the original GRH AI mini-interviews were collated and furnished to each workshop participant. This not only served as data, which they could consider along with their own responses and those of other workshop participants as they progressed through the AI 4D process, but also conveyed to each participant rich stories of "best experiences" within the organization, eg, stories from patients and their caregivers about exceptional oral health care experiences with the dental service clinicians and staffs.

Five key strategic topic areas are shown below. The AI questions shown for topics 1 and 4 are examples of the type of AI questions that were developed for each topic:

1. Access to care, including scope of services

- What do we do best now in providing access to care?

- How could we transform our current dental service to enhance access to care?

2. Effective utilization of technology

3. Clientele - How do we best meet their unique needs/ challenges, recruitment of patients, cost recovery, etc.

4. Service delivery in the context of superb customer service

- Where do we excel now in the delivery of patient services?

- Where do we excel now in customer service, ie, meeting and/or exceeding the patients' expectations?

- In what ways could we further develop the delivery of services to enhance both patient care and customer service?

5. Funding mechanisms and sources

There were 12 planning cluster participants in the first AI workshop. This was a relatively small planning cluster because the GRH dental service is a small clinical service within the hospital. Among this cluster were senior administrators and managers from both the GRH and the Faculty of Medicine and Dentistry, University dental faculty who work with the dental service, and the GRH site medical director and dental clinic staff. This range of participants in a group of only 12, with their widely differing schedules and responsibilities, illustrates why scheduling and time limitations are a major hurdle for whole-systems planning in the health care sector. The 12 participants were divided into four teams of three each. Each team started with a different topic and brainstormed ideas for the AI questions for that topic for 15 minutes. They recorded their responses on flip charts.
The teams then rotated to the next topic and considered the AI questions for their new topic. However, during the second round of brainstorming, if a team's strategic topic had previously been considered by another team, they would first review what the previous team had accomplished and then brainstorm ideas that would further develop and/or add new ideas to the previous team's ideas. This process was continued until each team had worked with each of the five strategic topics.

At the completion of the fifth 15-minute rotation, each team was then asked to summarize the flip-chart-recorded ideas for the topic for which they were the final group, ie, each team summarized the results from all four teams that had considered that topic. Since there were five topics and only four teams, one team was asked to summarize the results for two topics, which they easily accomplished. Twenty minutes was scheduled for this activity.

Fifty minutes was then utilized for team report-outs to the whole planning cluster and for any discussion necessary to clarify that the reports were complete and accurate. The workshop then concluded with a short discussion of next steps in the overall planning process. These next steps included assigning two members of the planning group to collate all the ideas generated by the workshop, distribute the collated document to all participants, and draft the potential AI propositions, ie, key future directions, for the GRH dental service. The planning cluster would then consider these propositions at the second workshop.

Another whole-systems method that can easily be combined with rapid-cycle brainstorming and AI is the World Café concept. World Café creates a "café-style" setting for numerous small groups (eg, of four individuals) to have rich networked conversations about topics that matter, eg, "our future directions."1 Having facilitated World Café workshops on leadership, we can attest to the positive influence of the "conversations over coffee" environment in small groups to encourage meaningful conversations on important organizational topics.

Several months later, the second and final AI workshop was held. We would have preferred a shorter time period between workshops, but the very full schedules of most participants precluded this. However, to refresh all of the participants with what had been accomplished during the first workshop, the collated ideas that had been generated were again sent to each participant, along with the draft-envisioned future propositions, ie, key directions for the future. The difficulty in scheduling the second workshop, even though the planning cluster involved only 12 individuals, reflects the very real problems faced across the health care sector 
in bringing people together. Schedules and commitments in health care are often very difficult to work around.

The format for this second workshop began with a short introduction reviewing what we had accomplished during the first workshop and then describing what we wanted to accomplish during the second workshop, ie, finalizing the key strategic directions and developing the initial action steps that must be pursued to begin the successful implementation of the new directions. This work was completed in a 2-hour time period, primarily because of the successful work accomplished during the first workshop, the effective preworkshop preparation that was done before both the first and second workshops, and the enthusiasm of the participants for building a very positive vision of the future for the GRH dental service.

Reflecting on the process, it was apparent that the participants came to the second workshop well prepared with ideas to modify the draft strategic directions so that they would best articulate their very positive vision of what the GRH dental service could become at its best. And, they came with definite ideas for actions to make their vision become reality. These actions had, in large part, been articulated during the brainstorming sessions held during the first workshop. At the second workshop, these action ideas were refined and agreed upon by consensus.

\section{The GRH dental service planning results}

When the planning cluster had successfully worked through all four phases of the AI 4D cycle, it had created a set of five key strategic directions, ie, AI-envisioned future propositions, that taken together describe a cohesive overall vision that the GRH dental service will follow over a number of years. This pathway focuses on exceptional access to, and quality of, dental care, oral health care delivery that exceeds the patient's expectations, development of the people, facilities and technology that make this possible, and the development of a national leadership position in oral health care for the elderly and persons with disabilities. Two examples of the finalized five key strategic directions, and the priority action steps for each, are included in Table 3.

It is important to note that it was recognized during this planning process that two important considerations must be addressed for successful implementation of the vision. First, the hospital and the dental service must continue immediately with the development of detailed logistics for implementing each of the plan's priority action steps and begin that implementation as rapidly as possible. Secondly, all involved must treat this plan for the future as a dynamic construct that is indeed the "blue-print" for future directions and for guiding decision making, but one that must be revisited frequently and modified as needed to capitalize on new opportunities and to respond to new challenges as they arise. Acting on these two considerations will ensure that the dental service will arrive at its new destiny.

\section{Discussion}

We want to be very clear that our intent in advocating the use of the rapid-cycle brainstorming process is to make it possible to use whole-systems change planning methods more easily in the time- and schedule-challenged health care arena, not to suggest that using this process will lead to better results than whole-systems methods as they are normally used. The real question is whether the rapid-cycle process does make whole-systems approaches more easily usable within health care organizations. To address that question, we will first reiterate our stated goals for this process: (1) to minimize the time required to effectively move through the sequential

Table 3 Key strategic directions and priority action steps for GRH dental service

\begin{tabular}{ll}
\hline Dental services key strategic directions & Implementation: priority action steps \\
\hline Access to care & - Develop strategy to ensure that target populations receive \\
- Strategic direction: The GRH, building on the premise that oral health & proper oral health care both at the GRH and within the \\
is critical to maintaining good overall health, continually strives to & capital health region. \\
improve access to a complete scope of oral health care services that & - Determine potential partners to support pursuit of above. \\
meet the unique needs of those it serves, particularly focusing on & Develop a combined medical/dental training model \\
the elderly and persons with disabilities. & (integration of medical and dental practitioners) \\
$\begin{array}{l}\text { Service exceeding patients'/stakeholders' expectations } \\
\text { - Strategic direction: The GRH strives to deliver people-centered oral }\end{array}$ \\
health care services to patients of such quality and "patient-friendliness" \\
that patient and stakeholder expectations are continually exceeded.
\end{tabular}

Abbreviation: GRH, Glenrose Rehabilitation Hospital. 
phases of the whole-systems process, while at the same time (2) to maximize the engagement of participants, (3) to develop creative synergism between small groups addressing specific planning topics, and when called for (4) to still be able to facilitate the involvement of large numbers of individuals across the organization.

Rapid-cycle brainstorming, as we have proposed it, would normally require only two workshops per planning cluster ranging in time from 2 hours to 1 half day per workshop. This presupposes that the appropriate prebrainstorming preparation has been done and that small working groups from the planning clusters prepare materials for the second workshop. Considerable preplanning is also necessary when using any traditionally applied whole-systems approach. The total time required for a planning cluster to hold two workshops is quite modest when compared with multiday whole-systems events. In addition, scheduling difficulties are reduced because not all of the planning participants in an organization are required to come together at the same time, but rather in planning cluster groups of usually 25 or fewer individuals.

The planning cluster size of approximately 25 or fewer is conducive to real engagement in the planning activities, particularly as compared with large groups where it is easier for individuals to become passive observers rather than active participants. In addition, the brainstorming teams themselves number only between three and five individuals, which make it very easy for even the more introverted individuals to participate in brainstorming discussions. Thus, the design of the rapid-cycle brainstorming helps to facilitate individual participants' engagement in the process, and we continue to seek additional ways to maximize participant engagement.

One indicator that the brainstorming teams appear to have developed at least some creative synergism between them is the observation that these teams were able to suggest positive modifications and/or additional new ideas in response to the ideas that the teams coming before them had generated on each brainstorming topic. Since creative synergism between the brainstorming teams is difficult to measure, no definitive statement can thus be made about how much this may have contributed to the process and the results. However, if creative synergism does occur between the successive groups on each topic, this should lead to more effective brainstorming than in more traditional brainstorming sessions. We are currently designing an educational research project around this question.

The final goal is to be able to facilitate the involvement of large numbers of individuals across the organization. Given that as many additional planning clusters can be added as necessary and that the planning cluster workshops can be spread over a period of time, it is clear that large numbers of individuals can indeed be accommodated in the planning process, while still providing scheduling flexibility. The bridging activities that we have described previously provide a mechanism to bring the results from all of the planning clusters together to create a unified vision for the organization.

A very reasonable question to ask is why use wholesystems group face-to-face planning sessions at all when we have available information technology (IT)-based online survey methods, discussion forums, virtual shared spaces, etc, through which data can be collected to inform the process of determining key future directions and supportive actions? We have already discussed the way that group interactions, eg, brainstorming activities, facilitate teamwork, the broad engagement of people, the sense of empowerment, and ownership of the results. There is also the productive idea generation relating to organizational effectiveness and innovation that occurs as individuals from across the organization discuss all aspects of the organization as they consider its future. In addition, educational research does indicate that survey data can be very different from interview data and that the interview data, in this study, was much more accurate in representing reality. ${ }^{28}$ That being said, we do believe that valuable data can indeed be collected using IT-based methods, particularly when great skill and care are invested in developing the survey instruments and when there is an appropriate balance between these survey methods and face-to-face whole-systems group methods. Unfortunately, we do not as yet know what that appropriate balance should be. Research in this area may allow us to use more IT-based data collection effectively in the future and help us to focus our whole-systems group interaction more precisely on those times and situations where face-to-face interaction will have the greatest positive impact.

The GRH dental service planning cluster's efforts demonstrated that the rapid-cycle brainstorming method could facilitate organizational planning in a manner that used time very efficiently, thus permitting the use of a whole-systems approach within the time-challenged health care environment. The use of multiple planning clusters not only increases the number of individuals who can participate but also decreases scheduling difficulties for those who wish to participate. The GRH has used the rapid-cycle method repeatedly in their planning efforts in other hospital units. We also used the same process for strategic educational planning for both medical and dental undergraduate and graduate programs and 
residencies, in a combined school of medicine and dentistry, an environment that imposed at least as severe restrictions on time and scheduling as faced in the GRH dental service hospital environment. The faculty council later adopted the educational strategic directions and action planning results directly into the school's overall strategic plan.

We believe the rapid-cycle brainstorming method provides a useful way for flexible whole-systems approaches to organizational change, such as AI, to be effectively applied in the health care environment. The intent here is to preserve the advantages of whole-systems methods, eg, the broad scope of engagement, empowerment, team-building and change planning across and at all levels within an organization, the development of ownership in the process and results, the encouragement of innovative ideas that can move an organization forward, and the development of a sense of optimism and enthusiasm about an organization's future, while at the same time doing so within the significant time and scheduling limitations so frequently encountered within the health care arena.

\section{Disclosure}

The authors report no conflicts of interest in this work.

\section{References}

1. Holman P, Devane T, Cady S. The Change Handbook: The Definitive Resource on Today's Best Methods for Engaging Whole Systems. San Francisco, CA: Berrett-Koehler Publishers; 2007.

2. Work911.com [homepage on Internet]. Casselman, ON, Canada: Bacal and Associate Site; 2002-2009. Available from: http://www.work911. com/planningmaster/Strategic_Planning_-_Implementing_and_ Execution/. Accessed Feb 1, 2010.

3. Bramson R, Buss T. Methods for whole systems change in public organizations and communities: an overview of the issues. Public Organ Rev Global J. 2002;2(3):211-221.

4. Schein E. How can organizations learn faster? The challenge of entering the green room. Sloan Manage Rev. 1993;34(2):85-92.

5. Senge P. The Fifth Discipline. New York, NY: Doubleday; 1990.

6. Emery F, Trist E. The causal texture of organizational environments. Hum Relat. 1965;18(1):21-32.

7. Cooperrider D, Whitney D. Appreciative Inquiry - A Positive Revolution in Change. San Francisco, CA: Berrett-Koehler Publishers; 2005.

8. Ludema J, Whitney D, Mohr B, Griffen T. The Appreciative Inquiry Summit-A Practitioner's Guide for Leading Large-Group Change. San Francisco, CA: Berrett-Koehler Publishers; 2003.

9. Cooperrider D, Whitney D, Stavros J. Appreciative Inquiry Handbook-For Leaders of Change. Brunswick, OH: Crown Custom Publishing; 2008.
10. Lindajoymitchell.org.uk [homepage on the Internet]. What is appreciative inquiry? 2007. Available from: http://www.lindajoymitchell.org.uk/ downloads/what-is-appreciative-inquiry.pdf. Accessed Feb 1, 2010.

11. Zakariasen K. Developing vision and strategy using an appreciative inquiry. Int J Knowl Cult Change Manag. 2006;6(3):191-195.

12. Owen H. Open Space Technology: A User's Guide, Revised and Expanded. 3rd ed. San Francisco, CA: Berrett-Koehler Publishers; 2008.

13. Barrett F, Fry R. Appreciative Inquiry: A Positive Approach to Building Cooperative Capacity. Chagrin Falls, OH: Taos Institute Publications; 2005.

14. Whitney D, Trosten-Bloom A. The Power of Appreciative Inquiry: A Practical Guide to Positive Change. San Francisco, CA: BerrettKoehler Publishers; 2003.

15. Nijstad B, Stroebe W, Lodewijkx H. Production blocking and idea generation: does blocking interfere with cognitive processes? J Exp Soc Psychol. 2003;39:531-548.

16. Diehl M, Stroebe W. Productivity loss in idea-generating groups: tracking down the blocking effect. J Pers Soc Psychol. 1991;61: $392-403$.

17. Mullen B, Johnson C, Salas E. Productivity loss in brainstorming groups: a meta-analytic integration. Basic Appl Soc Psych. 1991;12:3-23.

18. Luecke R. Harvard Business Essentials: Managing Change and Transitions. Boston, MA: Harvard Business School Press; 2003.

19. Slater R. The GE Way Fieldbook: Jack Welch's Battle Plan for Corporate Revolution. New York: McGraw-Hill; 2000.

20. Kouzes J, Posner B. The Leadership Challenge. San Francisco, CA: Jossey-Bass; 2007.

21. Hammonds K. Leaders for the Long Haul. Fast Company. 2001;48: 52-55.

22. Aacd.org [homepage on the Internet]. Madison, WI: American Academy of Cosmetic Dentistry; 2009. Available from: http:/www.aacd.com/. Accessed Feb 1, 2010.

23. En.wikipedia.org [web site on the Internet]. Wikipedia: The Free Encyclopedia; Available from: http://en.wikipedia.org/wiki/ Brainstorming\#Group_passing_technique. Modified Feb 4, 2010. Accessed Feb 5, 2010.

24. Smith MK. Peter Senge and the learning organization. 2001. Available from: http://www.infed.org/thinkers/senge.htm

25. Whitney D, Trosten-Bloom A, Cherney J, Fry R. Appreciative Team Building: Positive Questions to Bring Out the Best in Your Team. Lincoln, NE: iUniverse, Inc; 2004.

26. Whitney D, Cooperrider D, Kaplan B. An Encyclopedia of Positive Questions, Volume One: Using Appreciative Inquiry to Bring Out the Best in Your Organization. Brunswick, OH: Crown Custom Publishing, Inc; 2001.

27. Strauss A, Corbin J. Basics of Qualitative Research: Grounded Theory Procedures and Techniques. Newbury Park, CA: Sage Publications, Inc; 1990.

28. Wall L, Kelsey K. When findings collide: examining survey vs interview data in leadership education research. J South Agric Educ Res. 2004; 54(1):180-193.
Journal of Healthcare Leadership

\section{Publish your work in this journal}

The Journal of Healthcare Leadership is an international, peer-reviewed, open access journal focusing on leadership for the health profession. The journal is committed to the rapid publication of research focusing on but not limited to: Healthcare policy and law; Theoretical and practical aspects healthcare delivery; Interactions between healthcare and society and evidence-based practices;

\section{Dovepress}

Interdisciplinary decision-making; Philosophical and ethical issues; Hazard management; Research and opinion for health leadership; Leadership assessment. The manuscript management system is completely online and includes a very quick and fair peer-review system. Visit http://www.dovepress.com/ testimonials.php to read real quotes from published authors. 